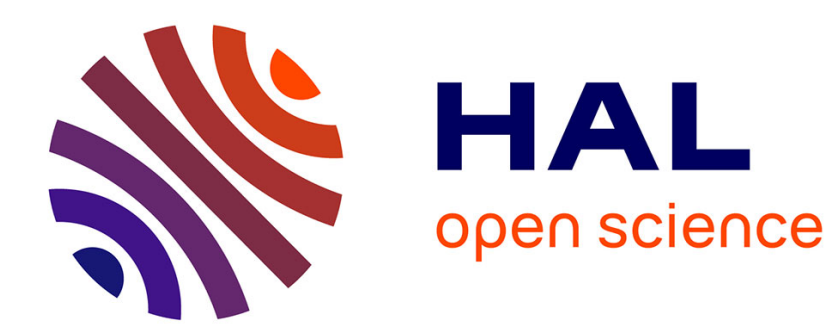

\title{
IONIC TRANSPORT IN CADMIUM FLUORIDE
}

\author{
M. Cyris, P. Müller, J. Teltow
}

\section{To cite this version:}

M. Cyris, P. Müller, J. Teltow. IONIC TRANSPORT IN CADMIUM FLUORIDE. Journal de Physique Colloques, 1973, 34 (C9), pp.C9-63-C9-67. 10.1051/jphyscol:1973909 . jpa-00215384

\section{HAL Id: jpa-00215384 https://hal.science/jpa-00215384}

Submitted on 1 Jan 1973

HAL is a multi-disciplinary open access archive for the deposit and dissemination of scientific research documents, whether they are published or not. The documents may come from teaching and research institutions in France or abroad, or from public or private research centers.
L'archive ouverte pluridisciplinaire HAL, est destinée au dépôt et à la diffusion de documents scientifiques de niveau recherche, publiés ou non, émanant des établissements d'enseignement et de recherche français ou étrangers, des laboratoires publics ou privés. 


\title{
IONIC TRANSPORT IN CADMIUM FLUORIDE
}

\author{
M. CYRIS, P. MÜLLER and J. TELTOW \\ Akademie der Wissenschaften der DDR Zentralinstitut für Elektronenphysik \\ Abteilung Transportprozesse DDR 1199 Berlin
}

\begin{abstract}
Résumé. - Ces dernières années, les études de $\mathrm{CdF}_{2}$ ont connu un grand essor en raison de sa faculté de se transformer d'un isolant à un semiconducteur. Cette conversion est permise par le désordre thermique du réseau, constitué de défauts de Frenkel dans le sous-réseau des anions. A l'encontre des études détaillées des propriétés optiques et diélectriques à basse température, les données à haute température sur le transport ionique intrinsèque et la structure du défaut dans ce cristal sont encore incomplètes et contradictoires. Dans cet article, des résultats expérimentaux récents sur la conductivité ionique et lautodiffusion dans $\mathrm{CdF}_{2}$ non converti sont réexaminés. Nous tentons de mettre des limites aux valeurs probables des paramètres du désordre et nous montrons que quelques aspects des résultats vont au-delà du domaine du transport ionique dans les solides accessibles par la théorie classique.
\end{abstract}

\begin{abstract}
In recent years, $\mathrm{CdF}_{2}$ has attracted considerable interest owing to its ability to be converted from an insulator to a semiconductor. This convertibility is rendered possible by the thermal disorder of the lattice, consisting of Frenkel defects in the anion sublattice. Contrary to extended investigations of the low-temperature electrical and optical properties, data on hightemperature intrinsic ionic transport and defect structure in this crystal are still incomplete and controversial. In this paper, recent experimental results on ionic conductivity and self-diffusion in unconverted $\mathrm{CdF}_{2}$ are revised. We try to set limits to the probable values of the disorder parameters and show that some features of the results go beyond the reach of the classical theory of ionic transport in solids.
\end{abstract}

Current interest in $\mathrm{CdF}_{2}$ dates from the discovery [1] that this ionic crystal can be converted to a semiconductor, in contrast to its otherwise striking similarity to $\mathrm{CaF}_{2}$, including Frenkel disorder in the anion sublattice. The conversion is achieved by doping the material with certain trivalent cations $\left(\mathrm{Mf}^{3+}\right)$ and annealing in $\mathrm{Cd}$ vapour at $\approx 500{ }^{\circ} \mathrm{C}$. This process follows the reaction equation

$$
\frac{1}{2} \mathrm{Cd}(\mathrm{g})+\mathrm{F}_{0}^{\prime} \leftrightharpoons \frac{1}{2} \mathrm{CdF}_{2}(\mathrm{f})+\mathrm{e}^{\prime}\left({ }^{1}\right) \text {. }
$$

expressing the replacement of interstitial fluorine ions $\mathrm{F}_{0}^{\prime}$ by electrons via diffusional migrations to and from the surface [2]. Reaction (1) is enabled energetically by the annihilation of a lattice defect per electron incorporated. A similar argument excludes the creation of anion vacancies $\square$ :a by a conversion reaction analogous to (1) [3]. This explains the necessity of $\mathrm{Mf}^{3+}$ additions $\left(\rightarrow \mathrm{Mf}_{\mathrm{c}}^{*}\right)$ in convertible $\mathrm{CdF}_{2}$ crystals in order to provide a sufficient concentration of chargecompensating $F_{0}^{\prime}$. The other important function of these additions is to act as shallow traps for the electrons, effecting the semiconducting properties [4] of the converted material.

From the foregoing, in is evident that accurate knowledge of the parameters for point defect formit-

(1) Subscripts a, c, 0 indicate the incorporation on anion. cation or interstitial site, superseripts. give the excess chatge. and $g$ means gas phase, $r$ surface. tion and migration would considerably improve the understanding and control of the conversion process. Unfortunately above $300^{\circ} \mathrm{C}$ the high aggressivity of $\mathrm{CdF}_{2}$ and of its dissociation products caluses increasing contamination because $\mathrm{Cd}$ vapour and $\mathrm{F}_{2}$ react with most vessel and electrode materials. This entails increasing danger of falsified and/or controversial results. In fact values of the defect formation enthalpy between 4.5 and $0.4 \mathrm{eV}$ have been derived from experimental results.

Figure 1 shows some typical conductivity datia by Cyris [5]. preferentially using evaporated silver electrodes. The curves pertaining to the same $\mathrm{Sm}^{3}$ doped crystal after annealing either in $\mathrm{Cl}_{2}$ or in $\mathrm{Cl}$ vapour exhibit the enormous influence of the conversion on the conductivity, enhancing it by more than $10^{10}$ at $20^{\circ} \mathrm{C}$. Therefore special precautions are needed to ensure pure ionic conductivity in $\mathrm{CdF}_{2}$ doped with $\mathrm{Mf}^{3+}$. An anneal in $\mathrm{Cl}_{2}$ gas $\left(500^{\circ} \mathrm{C} .1 \mathrm{~h}\right)$ prior to measurement has proven sufficient. Withoul such precaution, it is easy to obain various intermediate curves, corresponding to a partly converted state Results of this kind [7] include remarkable effects of storage and are probably due to electronic conduction.

The $\mathrm{Na}^{+}$and $\mathrm{Se}^{--}$doped erystals (Fig. I) conduce much better than the $\mathrm{Sm}^{3}$ and $\mathrm{In}^{3}$ doped ones. This indicates incorporation of $\mathrm{Na}$ on $\mathrm{Cd}^{++}$sites $\left(\mathrm{Na}_{\mathrm{c}}^{\prime}\right)$. of $\mathrm{Se}^{--}$on $\mathrm{F}^{-}$sites ( $\mathrm{Se}_{\mathrm{i}}^{\prime}$ ) and the mobility of the charge-compensating a surpassing by fill that of $\mathrm{H}_{1}$ 


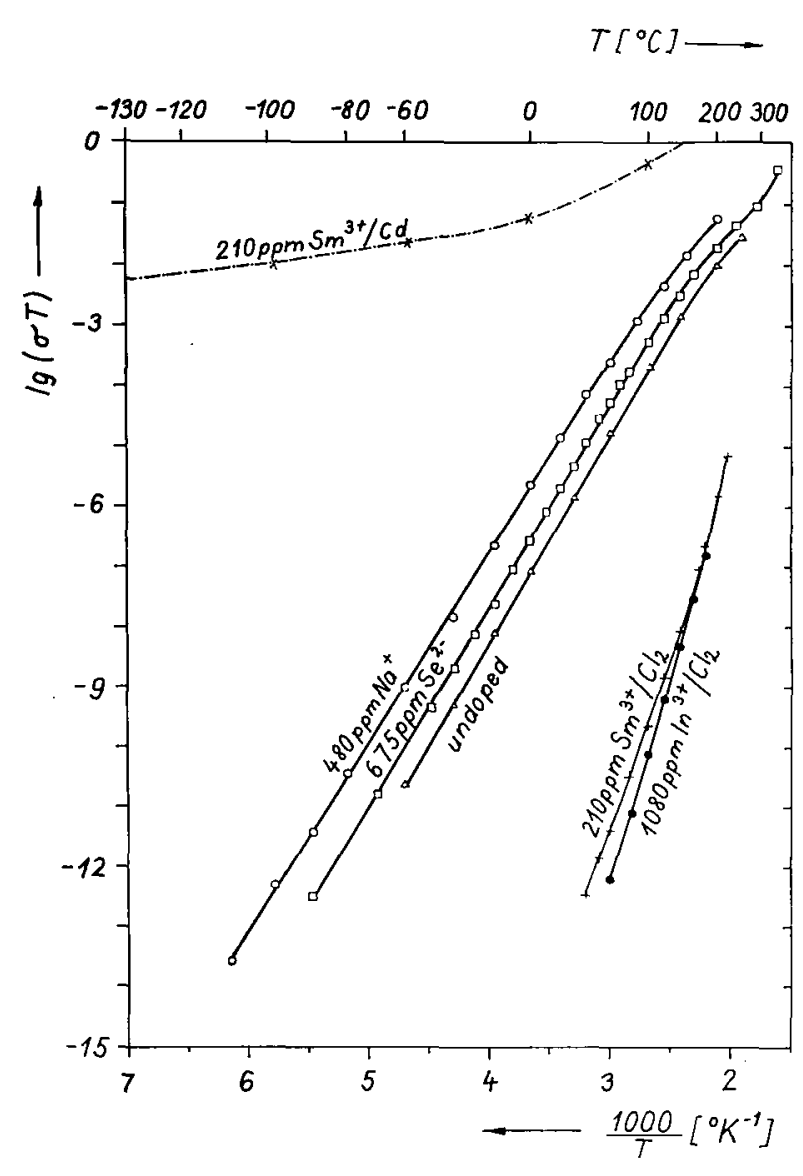

Fig. 1. - Conductivity of $\mathrm{CdF}_{2}$ crystals with various additions [5]. Nominal (as-weighed) concentrations. The $\mathrm{Mf}^{3+}$ doped crystals have been annealed in $\mathrm{Cl}_{2}$ or $\mathrm{Cd}$ vapour.

The excellent linearity of these curves over 10 to 14 powers of 10 is typical for the association region. From this slope and that of the short extrinsic dissociated region, values of the enthalpies of association and vacancy motion were derived by computer adaptation (Table I). These values compare moderately well with those obtained by other authors using similar conductivity results [6], [7] and the temperature dependence of the $\mathrm{F}^{-}$self diffusion coefficient [8], which increases with rising $\mathrm{Na}^{+}$addition as it should do in the extrinsic region.

The next columns in table I give the experimental slopes of the conductivity curves in the association regions, inherent also in ITC measurements [9]. The bracketed value occurs only at unusually low temperatures $\left(-80^{\circ} \mathrm{C}\right)$ and is perhaps disfigured by electronic contributions. As long as there is doubt about association of $\mathrm{Mf}^{3+}$ with $\mathrm{F}_{0}^{\prime}$, the last column represents an upper limit for $H_{\text {mo }}$, the enthalpy of $F_{0}^{\prime}$ motion, taking account of the bulge [10] to be expected near this region because of "salting-out " of the more mobile vacancies by $\mathrm{Mf}^{3+}$.

This moderate conformity of results by different authors is entirely lost if we turn to the intrinsic conductivity region, which reaches to the melting point (mp) $1078^{\circ} \mathrm{C}$ and is governed by the formation enthalpy $(H)$ and entropy $(S)$ of the anion Frenkel defects. Within this region no reliable bulk transport measurements exist and perhaps never will be possible. At the lower boundary $\approx 400{ }^{\circ} \mathrm{C}$, those by Tan and Kramp [6] are the most credible ones in virtue of special experimental precautions, including anneals in $F_{2}$ prior to measurements.

The remarkable features of these results (Fig. 2) are first, knees on the $\lg T(1 / T)$ curves of the $\mathrm{Y}^{3+}$ doped, undoped and weakly $\mathrm{Na}^{+}$doped crystals at $\approx 250^{\circ} \mathrm{C}$, followed by very steep rises $(2.69 \mathrm{eV})$ from $300^{\circ} \mathrm{C}$ upward, and second, intersections of these curves with those of the more strongly $\mathrm{Na}^{+}$doped samples. This rise, comparable only to a likewise extreme one found on $\mathrm{SrCl}_{2}$ [14], is interpreted by the authors as intrinsic, yielding the enormous formation enthalpy $4.5 \mathrm{eV}$ $(2.69=0.44+4.5 / 2)$, which surmounts appreciably the maximum value $2.8 \mathrm{eV}\left(\mathrm{CaF}_{2}\right)$ ascribed formerly

TABLE I

Enthalpies of motion and association in $\mathrm{eV}$

Enthalpy of motion $H_{\mathrm{m}} \quad$ association $H_{\mathrm{a} \square}$

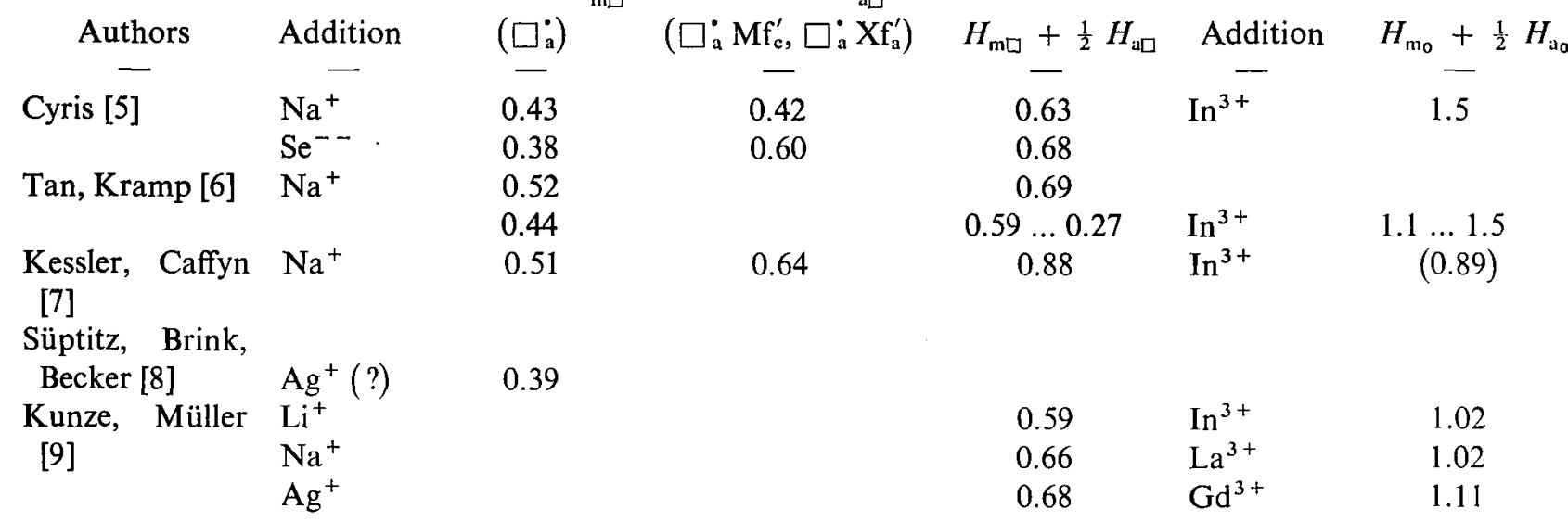




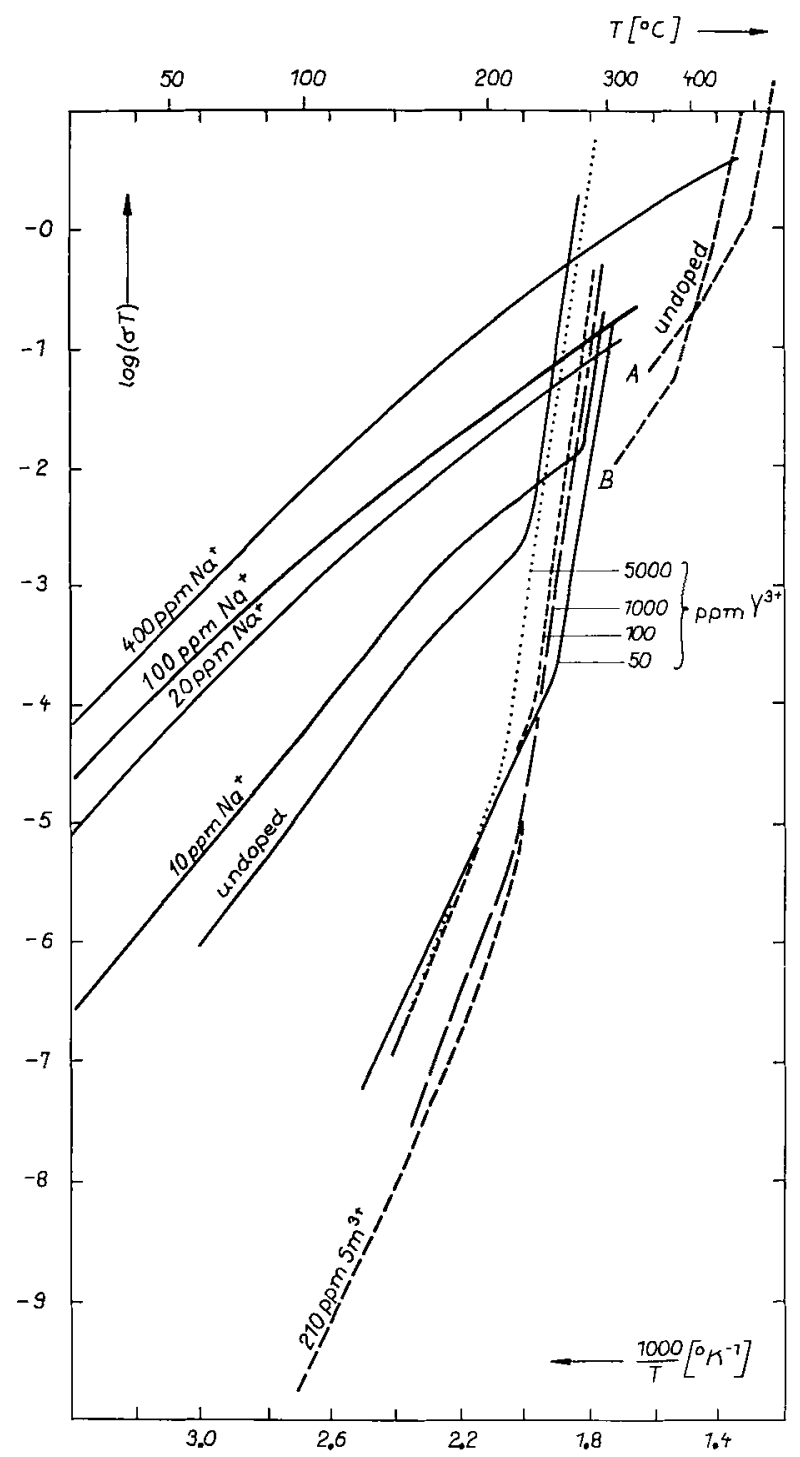

FIg. 2. - Conductivity of $\mathrm{CdF}_{2}$ with $\mathrm{Na}^{+}$and $\mathrm{Y}^{3+}$ additions (analyzed concentrations) after Tan and Kramp [6], compared to results by Cyris [5] (210 $\left.\mathrm{ppm} \mathrm{Sm}^{3+}\right)$ and Kessler and Caffyn [7] undoped, A fresh sample, thickness $0.133 \mathrm{~cm}, \mathrm{~B}$ used sample, $0.19 \mathrm{~cm})$.

to alkaline and alkaline-earth halides. Linear extrapolation of this rise to the $m p$ would yield an "ionic superconductivity $\gg$ of $\approx 10^{12} \Omega^{-1} \cdot \mathrm{cm}^{-1}$ at that temperature. Therefore the steep rise cannot be part of the intrinsic region, the more so because this would preclude the intersections, instead of section-free smooth junctions of the $\mathrm{Na}^{+}$curves into the common intrinsic branch to be expected [11]. Such crossing can only result from an interchange of the roles of the two defect species as faster and slower carriers below the intrinsic region. In order to arrive at the mp with a sane conductivity value, several (at least 2) interchanges of this kind should occur, implying heavily temperature-dependent enthalpies and entropies of motion, i. e. several competing jump mechanisms. Such rather ad hoc assumptions would be of litle use for computer analysis. A hypothetical solid-phase transformation of $\mathrm{CdF}_{2}$ below its mp would be an expe- dient, of course, but no such transformation is known for any compound crystallizing in the high-symmetrical fluorite lattice [15]. Therefore it seems inevitable to conclude that the steep rise $(2.69 \mathrm{eV})$, if not due to contamination or surface effects, is an electronic perturbation effect of unknown origin, perhaps somewhat reminding of $\mathrm{ZnO}$.

In this connection it is comforting that the steep rise is not seen on Kessler and Caffyn's conductivity curves of undoped crystals in the range 200 to $550{ }^{\circ} \mathrm{C}$ which, though not free from electrode effects, exhibit knees at $\approx 400^{\circ} \mathrm{C}$ followed by a high-temperature slope $1.9 \mathrm{eV}$ (Fig. 2). This would extrapolate to $\approx 10^{4} \Omega^{-1} \cdot \mathrm{cm}^{-1}$ at the $\mathrm{mp}$, still a quasi-metallic value, whereas the conductivities of other simple halide crystals hardly exceed $1 \Omega^{-1} \cdot \mathrm{cm}^{-1}$ at the $\mathrm{mp}$.

Another possibility of calculating the disorder parameters is offered by the conductivity isotherms of Tan and Kramp [6], exhibiting both branches of the Koch-Wagner hyperbola at 200, 175 and $150{ }^{\circ} \mathrm{C}$ and therefore enabling a complete analysis including defect association [13]. The first values of the (molar) defect concentration $x_{0}$ of the pure crystal, as obtained by separate analysis of the $\mathrm{Na}^{+}$branches [6], have been criticized [11] because of the resulting low $H(0.396 \mathrm{eV})$ involving a large negative $S$. For a crude estimate, we assume in figure 2 at $175^{\circ} \mathrm{C}$ the conductivity of a pure crystal to be $1 / 10$ of that of the undoped sample $\left({ }^{2}\right)$, i. e. $\sigma_{0}\left(175^{\circ} \mathrm{C}\right)=1.2 \times 10^{-6} \Omega^{-1} \cdot \mathrm{cm}^{-1}$. This corresponds to $x_{0}\left(175^{\circ} \mathrm{C}\right)=1.9 \times 10^{-7}, 1 / 10$ of the published [6] value. Then (Fig. 3) the assumption $S=5 k$, consistent with the defect formation entropy of comparable crystals, yields $H=1.41 \mathrm{eV}$. Hence $x_{0}(\mathrm{mp})$ would amount to 0.04 which is more than the maximum value 0.01 found on other simple ionic crystals like $\mathrm{CaF}_{2}$ [12]. Reducing $x_{0}$ (mp) to this value 0.01 entails other dilemmas (Fig. 3): Either $S$ almost vanishes, or $x_{0}\left(175^{\circ} \mathrm{C}\right)$, as estimated from the isotherms, is very wrong and should be replaced by $3 \times 10^{-9}$. This value, however, would lead to unreasonably large vacancy mobilities $\|_{\square}$ at 175 and 1078 "C. Therefore, if a compromising value of $H$ exists within the entire temperature range of solid $\mathrm{CdF}_{2}$, it should be close to $1.41 \mathrm{eV}$.

The fluorine self-diffusion experiments [8] traced the intrinsic region only from $450{ }^{\circ} \mathrm{C}$ upward and led to the estimate $H=2.1 \mathrm{eV}$ and $S=4.61 \mathrm{k}\left({ }^{3}\right.$ ) (Fig. 3). This gives a reasonable $x_{0}(\mathrm{mp})$. However the resulting $x_{0}\left(175^{\circ} \mathrm{C}\right)$ seems to be much too low to account for the conductivity data, requiring

$$
u_{\square}\left(175^{\circ} \mathrm{C}\right)>1 \mathrm{~cm}^{2} / \mathrm{Vs} \text {. }
$$

Finally, it is enlightening to compare the ionic conduction of $\mathrm{CdF}_{2}$ to that of $\mathrm{CaF}_{2}$ (Fig. 4) [12]. This

(2) Taking account of a probable unwanted impurity like $\mathrm{Na}:$ in the latter.

(3) Introducing in eq. (6) of reference [8] the correct precxponemial factor 2 instead of $!$. 


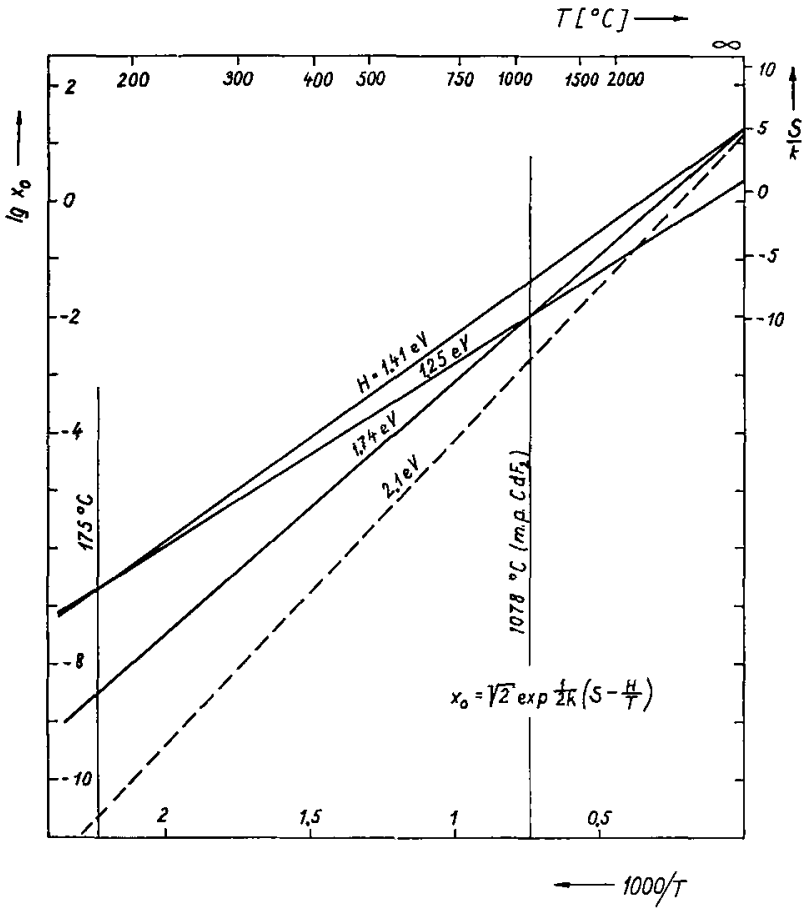

FIG. 3. - Extrapolation of the defect concentration $x_{0}$ to the melting point. $k$ Boltzmann constant.

material allows a much closer approach to its $\mathrm{mp}$ $1418^{\circ} \mathrm{C}$. The disorder parameters come out to be somewhat smaller than previous values : $H=2.43 \mathrm{eV}$, $S=7.95 k, H_{\mathrm{m} \square}=0.51 \mathrm{eV}, H_{\mathrm{mo}}=0.92 \mathrm{eV}$ [12]. The two charge carriers $\square \square_{\mathrm{i}}{ }^{\prime}$ and $\mathrm{F}_{0}^{\prime}$ interchange their faster/slower roles at $670^{\circ} \mathrm{C}$; a similar behaviour can be anticipated for $\mathrm{CdF}_{2}$ in view of the strong temperature dependence of the mobility ratio [6]. Figure 4 exhibits once more the anomaly of the steep conductivity rise of $\mathrm{CdF}_{2}$ above $250{ }^{\circ} \mathrm{C}$ which hardly can be ascribed to ionic conduction in the bulk. Furthermore, assuming comparable behaviour of the

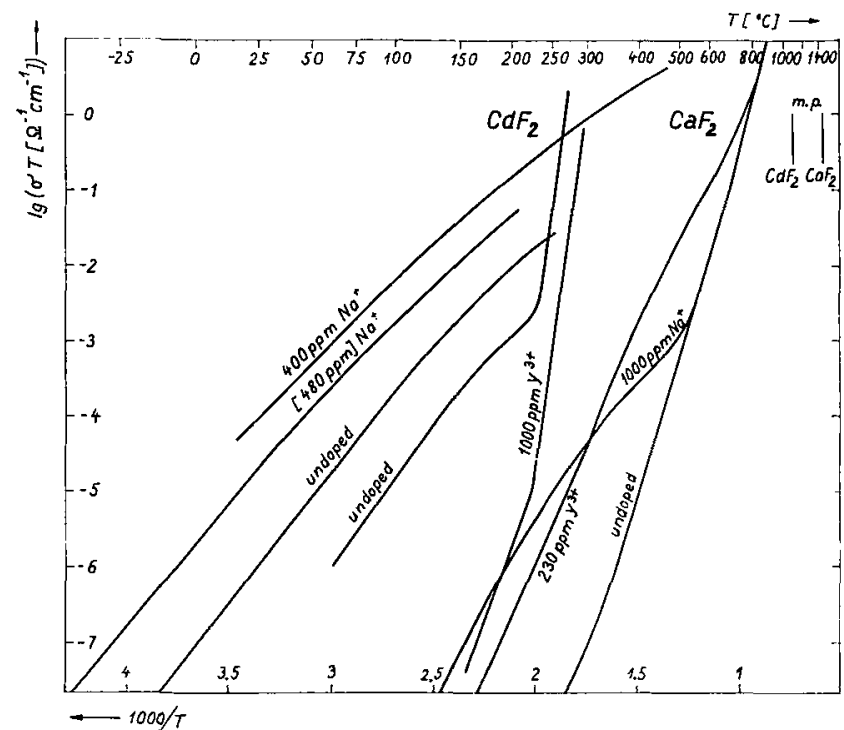

FIG. 4. - Comparison between the conductivities of $\mathrm{CdF}_{2}$ [5], [6] and $\mathrm{CaF}_{2}[12]$

mobilities, it is evident that for $\mathrm{CdF}_{2} H$ and $S$ must be considerably smaller than for $\mathrm{CaF}_{2}$.

Throughout this paper, estimates of disorder parameter values from various experimental sources were subjected to the criterion that the resulting defect concentrations and mobilities up to the melting point must remain within certain limits compatible with the lattice defect model. Likewise the enthalpies and entropies of defect formation, migration and association should not differ too much from the values found on other comparable ionic crystals and especially should not become negative. Faute de mieux, this procedure may prove to be helpful in other cases of unknown or inaccessible high-temperature transport data as well. At any rate, new and precautious experimental approaches to the high-temperature transport phenomena in $\mathrm{CdF}_{2}$ are urgently needed.

\section{References}

[1] Prener, J. S., Kingsley, J. D., J. Chem. Phys. 38 (1963) 667.

[2] Teltow, J., Ciyst. Latt. Defects 4 (1973) 197.

[3] Müller, P., Teltow, J., Cryst. Latt. Defects 3 (1972) 171.

[4] Lee, T. H., Moser, F., Phys. Rev. B 3 (1971) 347

[5] CYRIS, M., diploma thesis, Humboldt-Universität Berlin, 1970.

[6] Taiv, Y. T., Kramp, D., J. Chem. Phys. 53 (1970) 3691.

[7] Kessler, A., Caffyn, J. E., J. Phys. C 5 (1972) 1134.

[8] Süptitz, P., Brink, E., Becker, D., Phys. Stat. Sol. (b) 54 (1972) 713.

[9] Kunze, I., Müller, P., Phys. Stat. Sol. (a) 13 (1972) 197.
[10] Süptitz, P., Teltow, J., Phys. Stat. Sol. 23 (1967) 9.

[11] Müllter, P., J. Chem. Phys. 55 (1971) 5144. TAN, Y., ibid. 5145.

[12] Bollmann, W., Reimann, R., Phys. Stat. Sol. (a) 16 (1973) 187.

Bollmann, W., Henniger, H., Phys. Stat. Sol. (a) 11 (1972) 367.

[13] Stasiw, O., Teltow, J., Ann. Physik 1 (1947) 261.

[14] Hood, G. M., Morrison, J. A., J. Appl. Phys. 38 (1967) 4796

[15] However, see Dworkin, A. S., Bredig, M. A., J. Phys. Chem. 72 (1968) 1277 for a diffuse 2-like anomaly of the heat capacity of $\mathrm{CaF}_{2}, \mathrm{SrCl}_{2}$ and $\mathrm{K}_{2} \mathrm{~S} 150-200$ "C below the melting temperatures. 


\section{DISCUSSION}

A. Kessler. - I would like to remind, that the data of Caffyn and me used in figure 2 are the reciprocal values of the resistance of the samples per unit surface and thickness. That is because especially in the range we believe to be due to intrinsic conductivity there is a contribution of the "electrode resistance 》 to the measured resistance (see curves $A$ and $B$ ). An extrapolation of these data is therefore not very meaningful in my opinion.

As far as the steep rise found by Tan and Kramp is concerned we also observed such a steep increase at about $500^{\circ} \mathrm{C}$. Moreover the current began to rise spontaneously at fixed voltage and temperature. If the voltage was immediately removed the sample recovered its original resistance at lower temperature. If the voltage was sustained for some time the original values of the resistance were "restored» and after removing the crystal surface, appeared colored after the said procedure.

This shows that (1) some chemical reaction or electron injection takes place at high temperatures and (2) there are differences in the material used by the different authors due to sample preparation which are in my opinion still not understood or recognised.

J. Teltow. - I agree with you that all these conductivity data are of preliminary character and should be checked and supplemented under definite experimental conditions.

J. Z. DAmm. - The anomalies observed in the conductivity curves of the doped $\mathrm{CdF}_{2}$ crystals resemble the effects related with electron injection (electrolytic colouration) e. g. into $\mathrm{Sr}^{2+}$-doped $\mathrm{KCl}$ performed at flat electrodes. This is consistent with the observations of Kessler mentioned earlier. The electron injection is sensitive to the heating rate and the dopant concentration. Especially, the effect of the former parameter should be carefully checked in the case of the anomalies cited by Dr. Teltow.

H. Teltow. - Such injection would have caused thermal hysteresis effects. However, only reproducible conductivity data free from hysteresis have been plotted in figures 1 and 2 below $350^{\circ} \mathrm{C}$. 